\title{
As diferentes acepções da arte na obra de Flusser
}

Artigo Inédito

Thiago Reis

(D) 0000-0003-3114-9468

palavras-chave:

arte; poiesis;

artifício:

Vilém Flusser

keywords:

Ars; Poiesis:

Artifice;

Vilém Flusser

palabras clave: arte; poiesis; artificio; Vilém Flusser

*Universidade de Uberaba (UNIUBE), Brasil

DOI: $10.11606 /$ issn.2178-0447. ars.2020.156353

\section{The Different Meanings of Art in Flusser's Work}

Las distintas acepciones del arte en la obra de Flusser

A arte desempenha um papel fundamental no pensamento de Flusser. Todavia, essa noção assumirá concepções diferentes ao longo da obra do autor. Nosso propósito é o de investigar e apresentar uma "morfologia" dessas acepções, partindo de sua obra inaugural, Língua e Realidade (1963), até os escritos tardios, voltados para a filosofia dos media. Ao final, buscamos perceber pontos de ruptura, mas também convergências, na teoria estética flusseriana.

Art plays a key role in Flusser's thinking. However, this very notion will assume different conceptions throughout the author's work. Our purpose is to investigate and present a "morphology" of these meanings, starting with his inaugural work, Language and Reality (1963), republished in English in 2017, to the late writings, focused on the philosophy of the media. In the end, our purpose is to understand disruptions but also convergences in Flusser's aesthetic theory.

El arte desempeña un rol fundamental en el pensamiento de Flusser. Todavía, esa noción asumirá concepciones distintas a lo largo de su obra. Nuestro proposito es investigar y presentar una "morfología" de esas acepciones, empezando en su trabajo inaugural, Lengua y Realidad (1963), en traducción libre, hasta los escritos tardíos, orientados a la filosofía de los media. Al final, intentamos percibir puntos de ruptura, pero también convergencias, en la teoría estética flusseriana. 
Os limites da realidade são os mesmos daquilo que se pode pensar. A princípio, tal pensamento se assemelharia à tese wittgensteiniana de que "os limites da minha linguagem denotam os limites do meu mundo" (WITTGENSTEIN, 1968, §5.6), não fosse o fato de que Flusser vê, em diversos momentos de sua obra, a imersão no silêncio (no nada) como uma possibilidade de expandir os horizontes daquilo que se pode dizer e pensar, ou antes, como condição de possibilidade para a expansão dos horizontes da realidade (ou realidades, de acordo os apontamentos do autor em relação à variação ontológica entre as línguas existentes) -, consonante, portanto, à afirmação de Adorno: "a despeito de Wittgenstein, seria preciso dizer o que não pode ser dito" (ADORNO, 2009, p. 16). Em Lingua e Realidade, obra inaugural do pensamento de Flusser, esse movimento ocorrerá justamente por meio da atividade poética. Porém, antes de analisarmos o que Flusser entende por poesia, faz-se necessária uma análise, ainda que sucinta, das "regiões" que compõem a língua.

De acordo com o esquema proposto pelo filósofo, a língua estaria margeada por duas regiões que são "anteriores ou posteriores à língua" e, portanto, "são irreais, são nada" (FLUSSER, 1963, p. 144). Quanto mais em direção ao sul, mais próximo nos encontraríamos da irrealidade, sob a forma do silêncio inautêntico, do pensamento ainda não articulado, do "calar-se do animal e do cretino". Na antípoda, rumo ao norte, nos aproximaríamos do já não mais articulável, espécie de silêncio diante do sublime, do inabarcável, tal como o "calar-se de um Sto. Tomás, de um Wittgenstein, do Buda" (Ibidem, p. 144). Próximo aos polos, nas zonas da oração e do balbuciar, encontraremos, respectivamente, o silêncio ante a contemplação do absoluto e o caos desarticulado (semelhante aos bebês que ainda não aprenderam a falar). Adjacentes ao equador, eixo que representa propriamente o que conhecemos como realidade, estão as zonas da conversação e da conversa fiada, que designam, por um lado, a rede de intelectos a partir da qual surgem novas informações (por exemplo, a atividade científica) e, de outro, o conjunto de intelectos isolados, simulacro da conversação, no qual se repercutem ou propagam conteúdos banais, não informativos (a cultura de massa). Por fim, há as regiões descritas como salada de palavras e a poesia, sendo que aquela designa o momento em que o intelecto se esfacela, fato geralmente associado à loucura, ao passo que a poesia possui um caráter produtivo: cria a (língua que cria a) realidade.
162

Thiago Reis

As diferentes acepções da arte na obra de Flusser 
A poesia, em Flusser, possui um sentido bastante largo, englobando, além da poesia stricto sensu, a "filosofia produtiva" e a

n. 39 ciência especulativa. Para o autor, a poesia está relacionada a certa originalidade (em específico, à origem de conceitos e regras do pensamento), e o poeta (poietés), por conseguinte, é aquele que produz algo novo ao extravasar os limites da realidade, incrementando o jogo da conversação. Isso nos permite deduzir que, dentro da dimensão estética da "língua", a novidade aparece como critério fundamental para indicar a qualidade da criação artística (seja ela um poema, uma música, uma fórmula ou um conceito), e que a autenticidade da arte não está em sua característica mimética, e sim poiética”, produtora de novos sentidos. O pensamento de Flusser converge, em certo sentido, com aspectos da filosofia de Ernst Bloch, em específico quando o filósofo alemão trata sobre o novum (ou o radicalmente novo), categoria que fundamenta a ontologia do ainda-não, para a qual o nada (o branco da tela, a palavra não escrita, o som inaudito, ou seja, o ainda-não-existente) apresentase enquanto camada estético-utópica de uma realidade por ocorrer (BLOCH, 2005, p. 109 e ss.).

Não fosse a atividade poética a recolher no indizível "novos dizeres", a adensar ontologicamente o "nada" até concretizá-lo ao nível dos intelectos em conversação, a realidade acabaria por entrar em um estágio redundante, impedindo a formação de novos pensamentos. O filósofo, contudo, não nos indica de que modo algo pode surgir do inefável (ex nihilo), mas apenas tangencia a atividade poética ao classificá-la como uma mutação da conversação, processo que se dá em quatro estágios: recolhimento (isolamento em relação à conversação), encolhimento (ou adensamento, que permite à língua novas conexões), impermeabilização (incompreensão pelo intelecto) e superação (mudança de posição do intelecto).

O poeta é, pois, um positor, que fornece a matéria-prima para os compositores, isto é, os intelectos em conversação. Do ponto de vista da poesia é a conversação, inclusive a científica e filosófica do tipo já mencionado, uma variação sobre temas propostos pela poesia. $\mathrm{O}$ poeta propõe, a conversação compõe. [...] A atividade da conversação é prosaica (de prosus, plano), restringe-se a duas dimensões, espalha a realidade num plano. A atividade poética é produtiva "sensu stricto", arranca algo (es) das profundezas do inarticulado (Eliot: The depth of unspoken). Produzir vem de producere (levar para a superfície). A poesia é, pois, a produção da língua. De onde produz o poeta a língua? Ex nihilo, daquele nada indizível que é o Alfa e o Ômega da língua. (FLUSSER, 1963, pp. 207-208) 
Note-se, ainda, que a poesia pode não apenas se transformar em direção à conversação, mas também em oração, sendo que, "no primeiro caso, o poeta cria língua para enriquecê-la; no segundo, luta por superá-la, embora continue criando" (Ibidem, pp. 181-182). Destarte, quando concretizar-se novamente em conversação, a poesia terá assumido uma posição radical, dir-se-á paradigmática, como é o caso de Shakespeare, "que lança uma torrente de língua nova sobre a conversação inglesa, transformando-a profundamente, ampliando-a e estendendo-a radicalmente" (Ibidem, p. 182).

Além do movimento "vertical" do globo da língua, o filósofo aponta ainda para duas tendências horizontais: rumo ao ocidente, as artes plásticas e, ao oriente, a música. Nesse sentido, intenta indicar a realização da língua em sentido "lato", isto é, toda uma região de símbolos para além do aspecto verbal. Em resumo, essas duas tendências amplificariam os índices sonoros e visuais da língua, a princípio afastando-se desta, rumo a uma tendência "abstrata" ou mais formalizada, para de novo tornarem a ser "lidas":
164

Thiago Reis

As diferentes acepções da arte na obra de Flusser

\begin{abstract}
Se, por exemplo, formos perseguir a língua na camada da poesia em direção à música, encontraremos os seguintes fenômenos (enumerados de maneira muito sumária): poesia épica, poesia lírica, canção, canção sem palavras, sonata executada instrumentalmente e talvez, por fim, um tipo de composição que, para ser apreciada, não precisará de execução. Poderá ser apreciada tal qual foi proposta pelo poeta, em anotações musicais, poderá ser lida. Enumeremos da mesma maneira sumária os fenômenos que encontraremos ao perseguir a língua na camada da poesia em direção à plástica: soneto, poesia concreta, pintura concreta, pintura abstrata e, possivelmente, pintura tão abstrata que não precisará ser executada. Poderá ser apreciada tal qual foi proposta pelo poeta, em anotações de geometria analítica, poderá ser lida. (FLUSSER, 1963, pp. 207-208)
\end{abstract}

Dois aspectos, quando se trata das extensões "poéticas" da língua, chamam a atenção. Por um lado, encontraremos aí o gérmen de uma das teses defendidas por Flusser em sua filosofia futura, no que diz respeito ao desenvolvimento das artes na articulação daquilo que posteriormente será caracterizado como o contexto póshistórico: de que estas acabariam por superar a materialidade para se converterem em informação pura, em arte pura, dada a mutação dos aspectos sonoros e visuais em atividade poética altamente codificada - algo próximo ao estágio final no desenvolvimento das artes em Hegel, isto é, de um movimento que tende a superar a característica sensível destas rumo à sua espiritualização, rumo ao pensamento. De 

se mostra consciente das transformações possíveis no tecido poético tradicional com o surgimento daquilo que denominou de "poesia científica” e "conversação do tipo técnico", além de problematizar o surgimento das "máquinas automizadas". Mesmo que, nesse momento, não reflita de forma aprofundada sobre estes aspectos (por "ser tarefa do futuro"), o filósofo não deixa de formular hipóteses sobre os seus possíveis desdobramentos, cujo aprofundamento só se daria após quase duas décadas, com o avanço das revoluções técnicas e o consequente desenvolvimento da sua filosofia dos media.

Os produtos da conversação científica do lado plástico, as máquinas automizadas, participarão em breve, da atividade produtiva dessa camada como se fossem intelectos. A apreciação ontológica desse novo desenvolvimento das línguas flexionais é tarefa do futuro. Podemos, entretanto, aventurar duas hipóteses poéticas: (a) este novo tipo de intelecto substituirá o tipo atual, deslocando-o para a camada da conversa fiada. Nesta hipótese aquilo que chamamos humanidade se transformará num a gente inautêntico e irrealizado, ou (b) este novo tipo de intelecto substituirá o atual, deslocando-o em direção à camada da poesia. Nesta hipótese aquilo que chamamos humanidade se realizará mais plenamente graças ao novo tipo de intelecto produzido. (FLUSSER, 1963, p. 206)

A descrição do globo da língua nos permite situar certos aspectos da dimensão estética flusseriana em sua primeira fase do pensamento e da importância dos processos de alargamento dos limites da realidade por meio da atividade poética contra o assentamento da redundância. Em suma, por meio da arte, o mundo poderá ser recriado inúmeras vezes, posto que ela carrega em si a capacidade de ampliar os limites da percepção humana, incrementando a vida com novos modelos de vivência. Os produtos da arte são, nesse sentido, esforços "para inventar novos meios de comunicar experiências não articuladas até então; para dizer o que não foi dito; para pronunciar o inefável" (FLUSSER, 2016, p. 25).

Cabe, no entanto, analisar de que maneira esse processo ocorre, ou seja, qual é a fons et origo que anima o impulso artístico - bem como de sua importância para a nossa sobrevivência diante do cenário póshistórico emergente. Para tal empreendimento, encontraremos alguns indicativos em Pós-história, sobretudo quando o autor se debruça sobre os "meios entorpecentes" utilizados enquanto recurso para atenuar, nos sujeitos, as tensões interpostas pela cultura. Duarte observa que "a possibilidade de decifração das imagens técnicas e, portanto, da 
contraposição ao seu efeito programador passa pela discussão sobre as formas de inebriamento na situação pós-histórica" (DUARTE, 2012, p. 218), remontando, por conseguinte, à tese freudiana que, desenvolvida em Mal-estar na civilização, sugere que o uso de "substâncias tóxicas" se apresenta como umas das saídas possíveis às decepções, sofrimentos e outras tarefas árduas interpostas pela vida, justamente por serem capazes de nos tornarem indiferentes à realidade.

Contra o temível mundo externo, só podemos defender-nos por algum tipo de afastamento dele [...]. O serviço prestado pelos veículos intoxicantes na luta pela felicidade e no afastamento da desgraça é tão altamente apreciado como um benefício, que tanto indivíduos quanto povos lhe concederam um lugar permanente na economia de sua libido. Devemos a tais veículos não só a produção imediata de prazer, mas também um grau altamente desejado de independência do mundo externo, pois se sabe que, com o auxílio desse "amortecedor de preocupações", é possível, em qualquer ocasião, afastar-se da pressão da realidade e encontrar refúgio num mundo próprio, com melhores condições de sensibilidade. (FREUD, 2010, p. 32-33)

De maneira similar, Flusser dirá que, para além dos instrumentos construídos pelo ser humano para produzir a cultura, ele também "produz instrumentos para escapar à tensão produzida pelos seus instrumentos" (FLUSSER, 2011 a, p. 153). As drogas, nesse caso, seriam capazes de atravessar o véu que codifica o mundo rumo ao “concreto", para nele se dissolver a partir de uma vivência sem mediações, aos moldes de uma unio mystica. A visão de tal experiência, todavia, aparecerá aos olhos dos sóbrios como contemplação repugnante. Essa repulsa diante do êxtase do ébrio se deve ao fato de que ele revela aos "sãos", todas as "contorções" (todos os recalques) da existência humana frente à edificação da cultura. De outra parte, é preciso ressaltar que a posição assumida pelo inebriado é sobretudo antipolítica, uma vez que este recusa o espaço público, voltando-se unicamente para sua experiência privada. Mas, ainda assim, apresenta-se como um gesto de protesto, observável publicamente, no qual o inebriado "demonstra a possibilidade dos aparelhos serem transcendidos", e, dessa forma, "se assemelha ao gesto do suicida: aponta publicamente para o 'além', não apenas o 'além' da república, mas igualmente o 'além' dos aparelhos” (Ibidem, p. 158).

A arte, por sua vez, demonstra ser um tipo de droga peculiar. Sua caracterização enquanto inebriante se deve ao fato de que ela
166

Thiago Reis

As diferentes acepções da arte na obra de Flusser 
ARS possui, como outras drogas, "viscosidade ontológica", ou seja, no ano 18 glossário flusseriano, a capacidade de mediar o imediato. A diferença n. 39 está no fato de que a arte (I) é capaz de gerar uma transitividade entre o imediato e o mediado, ou seja, de resgatar a experiência concreta, privada, codificando-a ou tornando-a publicável no mundo da cultura, modificando, como observa Duarte, “a percepção dos 'dados brutos' (como a matéria prima para a dimensão ontológica da língua) de um modo tal que, ao refuncionalizar a mediação pela cultura, dá a impressão de uma experiência imediata privilegiada da 'realidade" (DUARTE, 2012, p. 219); além do mais, (II) a arte é droga que possui certa aceitação social, não vista, portanto, enquanto espetáculo nauseante, mas como "beleza". Cabe ressaltar que ambos os aspectos, mutatis mutantis, se vistos conjuntamente, assemelham-se à noção freudiana de sublimação, ou seja, essa capacidade da arte em promover um desvio pulsional socialmente aceito, ao tornar manifesto (visível) o inconsciente. Trata-se, portanto, de um movimento:

[...] que se dirige para o "além" do espaço público rumo ao privado, e que agarra um pedaço do pedaço do espaço privado, "uma experiência imediata", para lançá-lo sobre o espaço público em forma codificada. Tal gesto é interpretável de várias maneiras. Como gesto que apanha "ruído" e o transforma em "informação" (interpretação aparelhística esta). Ou como gesto que transforma "experiência" em "modelo". Ou como gesto de sonhador que transforma "fantasma" em "símbolo". A arte é o órgão sensorial da cultura, por intermédio do qual ela sorve o concreto imediato. A viscosidade ambivalente da arte está na raiz da viscosidade ambivalente da cultura toda. (FLUSSER, 2011 a, p. 159)

Ao referir-se à "viscosidade ambivalente" da arte, o filósofo quer indicar o movimento ao mesmo tempo necessário e perigoso em relação à cultura: por meio da produção artística, a cultura pode ser incrementada com novos modelos, experiências etc., mas, concomitantemente, corre o risco de ter desestabilizado o projeto ou programa inscrito em seu funcionamento. Em todo caso, a cultura não pode se furtar de tal movimento, "porque sem tal fonte de informação nova, embora ontologicamente suspeita, a cultura cairia em entropia” (Ibidem, p. 159). É importante destacar que, diante da dimensão aparelhística, cuja tendência é absorver todo e qualquer gesto para o interior dos aparelhos, a arte apresenta-se, segundo Flusser, enquanto gesto inassimilável e, desse modo, enquanto gesto emancipatório, pois "publicar o privado é o único engajamento na república que efetivamente implica transformação 
da república, porque é o único gesto que informa”. À medida que os aparelhos "permitem tal gesto", colocam em xeque "a sua função despolitizadora" ${ }^{1}$. Em outras palavras, a arte seria capaz de subverter a lógica de funcionamento automático e redundante dos aparelhos, promovendo uma ruptura ao inserir aí elementos até então imprevisíveis. Ao caracterizar a arte enquanto embriaguez (negação da cultura que alimenta a cultura) - processo através do qual o sujeito mergulha em sua experiência concreta e privada para daí extrair e publicar novas formas de vivência -, as formulações de Flusser ainda estão próximas à visão apresentada em Língua e Realidade, ou seja, a do processo artístico (criatividade) enquanto coisa transcendental, espontânea, inspirada.

Todavia, em obras como O Universo das imagens técnicas e A Escrita, surge outra conotação: a da arte vista enquanto jogo ou estratégia, em que o artista assume o papel de um jogador (por meio de aparelhos e programas) cuja meta é variar o repertório da realidade, atualizando-o em novos modelos de vivência. O processo artístico, nesse contexto, é tomado como algo artificial, deliberado, variacional, não intuitivo (a partir de uma visão teórico-científica, informática, cibernética etc.) (Cf. FLUSSER, 1998). Para ambos os casos permanece correta a afirmação de que a arte é um esforço criativo contra a tendência à desinformação, além de recurso potencial e importantíssimo diante de uma realidade aparelhada. Vejamos alguns dos desdobramentos relativos à assumpção da arte enquanto artifício.

Ao assumir o lado artificial da arte, diferentemente do que foi posto em outros momentos, o filósofo tem por intenção dessacralizar o que se entende por produção artística, ao mesmo tempo que tenta expandir a concepção do que se entende por arte para além de seus pressupostos tradicionais. Pretende com isso resgatar uma noção de arte que esteja aliada à ciência sob a perspectiva da techné. Como reiteradas vezes afirma o autor, a "história da cultura" pode ser descrita como o embate persistente entre o que é e o que deve-ser, ou seja, um esforço malicioso para modificar as circunstâncias objetivas ("naturais") que fazem face à existência humana, para transformar os obstáculos que se encontram lançados, por assim dizer, no meio do caminho (ob-jectum). E o modo pelo qual os objetos são alterados, a forma com a qual os sujeitos superam tais obstáculos, denominar-se-á arte (techné $)^{2}$.

O termo techné designa a capacidade de fazer surgir algo - mais especificamente, a partir da transformação da natureza em algo artificial: 

amorfo que recebe do artista, o técnico, uma forma, ou melhor, em que o artista provoca o aparecimento da forma” (FLUSSER, 2008a, p. 182). Poder-se-ia dizer, desse modo, que o artista é aquele que, por meio de seu fazer, engana a matéria, subverte as formas naturais: uma alavanca, por exemplo, é uma arte "capaz de enganar a gravidade, trapacear as leis da natureza, ardilosamente”, e o artista apresenta-se, sobretudo, enquanto um conspirador malicioso: "ser humano é um design contra a natureza". O termo latino equivalente ao grego, "Ars", resguardará a mesma conotação: “quer dizer [...] 'articulabilidade' ou 'agilidade' e artifex ('artista') quer dizer 'impostor" e "o verdadeiro artista é um prestidigitador, o que se pode perceber por meio das palavras 'artifício', 'artificial' e até mesmo 'artilharia”" (Ibidem, p. 183). Se analisarmos etimologicamente as palavras máquina e mecânica (mechos), correlacionadas ao termo techné, veremos que resguarda sentido similar: "Ulisses é chamado polymechanikos, [...] "o astucioso" (Ibidem, p. 182).

A arte pode ser compreendida, nesse ínterim, como uma prática deliberada que intenta superar os obstáculos da realidade e, em último caso, refere-se a todo e qualquer artifício capaz de transformar a nossa condição enquanto seres determinados em agentes livres, libertos da submissão da natureza, dos objetos etc. Por consequência, tal processo de artificialização, a do ser humano enquanto artifício realizado e sua consequente implicação sobre os processos materiais da sociedade, tende a nos libertar para aquilo que seria o propósito fundamental da existência humana, de acordo com a ética flusseriana: o de que possamos nos voltar sobre nós mesmos: "seremos liberados da negação, do estar aqui contra, e liberados para o diálogo, o estar aqui com os outros" (FLUSSER, sem data, sem paginação). A telemática, como vimos, será o meio a partir do qual tornar-se-á possível a concretização de tal existência intersubjetiva:

[...] para, em diálogo com os outros elaborarmos informações sempre novas, e informações imateriais, não negadoras de objetos. As imagens dialogicamente sintetizadas em terminais são disto exemplo precoce. $\mathrm{O}$ homem enquanto artifício realizado será elo em diálogo produtor de arte pura. Pois tais informações imateriais sintetizadas, tal arte pura criada deliberadamente por diálogo, não mais será técnica que visa alterar o mundo objetivo a fim de alterar o homem. Será técnica que visa dar sentido à vida intersubjetiva. (Ibidem, sem paginação). 
Como a passagem supracitada indica, a artificialização da vida acabará por deslocar paulatinamente a pré-ocupação com a cultura material (que pautou o desenvolvimento da humanidade desde o seu início) rumo aos problemas relacionados ao processamento de informações, ou seja, rumo à cultura imaterial. Isso se dará, como apontado, pelo fato de que (I) o trabalho será substituído por aparelhos, mas também porque (II) há um desinteresse crescente na cultura material, que pode ser notado desde a primeira Revolução Industrial, quando a realidade passou a ser inundada por uma maré de objetos que, ao serem reproduzidos de forma incontável e automática, tornaram-se cada vez mais baratos e efêmeros, objetos de mero consumo, úteis até que se esgotem ou se tornem descartáveis. E é justamente essa torrente de objetos desvalorizados (sem "aura") que levaria ao desinteresse pela cultura objetiva em prol de um interesse cada vez maior na cultura imaterial (na informação).

Em suma, a produção de artefatos que visava ao mundo dos objetos (contra os objetos, a fim de transformá-los), em situação futura estará voltada puramente para a modificação de informações, e o artista tornar-se-á um manipulador de códigos, a fim de modificá-los como num jogo deliberado em que novas estratégias serão traçadas para a luta do ser humano contra a morte e o esquecimento: "artista não mais é artesão que imprime informações sobre objetos (pedras, telas, palavras, sons musicais ou odores). 'Artista' doravante é jogador que visa situações improváveis no jogo no qual está engajado" (FLUSSER, sem data, sem paginação). Esse ponto já havia sido tangenciado na alegoria do Vampyroteuthis Infernalis. Na fábula, Flusser ressalta que a diferença entre o ser humano e o octópode estaria no fato de diferirem quanto aos métodos de preservação e armazenamento da memória, uma vez que ambos estão engajados contra o esquecimento. "Os homens", dirá o filósofo, "confiam um pouco mais que o Vampyroteuthis na permanência dos objetos" (FLUSSER, 2011b, p. 110), de modo que, ao longo de sua história, toda vivência se realiza para um determinado objeto (seja ele o mármore, o bronze, o papel, os sons, a língua):

E todo objeto que o homem encontra no seu caminho rumo à morte contém implicitamente as categorias que permitem articular determinadas vivências: determinado sentimento, pensamento, valor, desejo. Não é que o homem passe primeiro por uma vivência qualquer, e depois procure por um objeto apropriado para nele exprimi-la. O homem vivencia, desde já, em função de determinado objeto. Vivencia como escultor de mármore,
Thiago Reis

As diferentes acepções da arte na obra de Flusser 
como orador ou escritor português, como músico, como produtor de filmes [...]. // Surge destarte feedback entre homem e objeto, no curso do qual o homem vai informando o objeto, e vai sorvendo vivências nele que vai novamente utilizar para informar o objeto. Tal feedback é a essência da arte. (Ibidem, p. 111 )

O interesse do Vampyroteuthis, por sua vez, não está em informar objetos. Para o octópode a confiança na permanência do mundo dos objetos é irrisória, de forma que a sua atividade criadora, a maneira pela qual ele armazena vivências adquiridas, transpassa os objetos e se dirige fundamentalmente rumo ao outro, pois é na luta contra o outro que ele se realiza: "tal feedback entre emissor e receptor, tal diálogo, é a essência da arte do Vampyroteuthis" (Ibidem, p. 114). Ao se servir de luzes, cores e nuvens de sépia, esses media "efêmeros e transpassáveis" (quase-imaterialidades) produzidos por suas próprias glândulas, o Vampyroteuthis procura informar o outro, a memória do outro. Esse deverá ser, mutatis mutantis, o modelo futuro do artifício humano. Como aponta Flusser, "[...] na medida em que a arte humana diverge da vampyrotêuthica, ela é empresa confusa e indisciplinada, e na medida em que a arte humana vai adquirindo autoconsciência e disciplina, vai convergir com a arte do Vampyroteuthis" (FLUSSER, 2011 b, p. 118). Ou seja, a autoconsciência da arte humana se dará quando o interesse dos seres humanos não mais se desviar para os objetos, mas para o outro. Isso revelaria, ainda, que a história da arte foi, até agora, uma história de mal-entendidos, pois fazer arte é, de acordo com o filósofo, realizar teoria da comunicação.

Entretanto, a maneira pela qual o octópode dispõe de sua arte é estratégia que visa, por meio da sedução e do engano, incutir (copular) violentamente informações. Isso não é, obviamente, uma exclusividade da arte vampyrotêuthica, caso tomemos o modo de funcionamento da cultura de massa. Mas, se observada de um ponto de vista diferente, em que o outro não mais seja "apenas o adversário a ser violentado para ser informado, mas também aliado que informa junto conosco", a noção mesma de estratégia ganha nova significação, qual seja, a do engajamento conjunto, cujo propósito é dispor, de modo sempre renovado, os termos da realidade na luta contra o deixar-de-ser, isto é, contra o esquecimento e a desinformação. "Estratégia”, define o filósofo, "é o grito de guerra que o homem lança na cara do universo, é ela arte que o homem manhoso, (o homem verdadeiro, humano), emprega para 
enganar o mundo" (FLUSSER, sem data, sem paginação).

Se a estratégia adotada pelos seres humanos no campo da cultura material se voltava contra os objetos, a fim de de informá-los para que, em sua durabilidade, os artefatos persistissem à desintegração, armazenando e transmitido informações ao longo do tempo, no campo das memórias eletromagnéticas (que, segundo Flusser, são muito mais resistentes à entropia do que a argila, o mármore ou bronze ${ }^{3}$ ) e da produção das imagens sintetizadas, a estratégia assumida deverá ser outra: desenvolver técnicas que manipulem as regras do jogo dos códigos existentes. Mas não apenas dos códigos pós-alfabéticos, uma vez que o filósofo aponta também para as possibilidades abarcadas pelas novas técnicas de manipulação dos seres vivos, como o mostra a revolução biotécnica ${ }^{4}$.

Os processos de artificialização da vida, vistos dessa perspectiva, tornam-se altamente intensificados, já que a vida deixará de ser o resultado da "estúpida automaticidade do processo vital" e passará a ser o resultado da combinação deliberada e sempre renovada de novos elementos. A artificialização dos processos biológicos já pode ser notada, como observa Flusser, nos "métodos da contracepção, na inseminação artificial, e um pouco mais tarde na incubação "in vitro”, técnicas que libertam a mulher para o gozo da sexualidade, fazendo com que o ato sexual assuma outra conotação: "passará a ser ele arte, técnica pura, jogo puro” (Ibidem). Das possibilidades antevistas por tal arte deliberada, pode-se elencar também modificação da certeza da morte em "acidente tecnicamente evitável”, o que resultará em alteração radical da nossa forma de estar-no-mundo: em suma, a vida passará a ser vista enquanto código passível de ser computado, de deliberação, em um jogo cujas regras poderão ser alteradas (bem como, por desdobramento, as regras do amor e da morte).

A nova revolução cultural se deve a técnicas que manipulam, (entre outras coisas), as regras do jogo do qual os seres animados, (plantas, animais e homens), são situações fenomenalizadas. São técnicas que ultrapassam o aspecto fenomenal do outrora chamado "real", para penetrarem o campo relacional concreto sobre o qual os fenômenos repousam. Por isto "arte" e "ciência" deixam de ser atividades que estudam e manipulam fenômenos, e passam a ser atividades que mergulham deliberadamente no campo relacional para brincarem com suas virtualidades. Arte, técnica e ciência em geral se "imaterializam" [...]. "Imaterializam-se" sobretudo porque "artefato" não mais significa "obra", e passa a significar "estratégia de jogo". (FLUSSER, sem data, sem paginação)
As diferentes acepções da arte na obra de Flusser

3. Não haveria, contudo, consistência para tal afirmação, isto é, de que as memórias eletromagnéticas são mais "perenes" que em outros suportes. Sobretudo se considerarmos que a imaterialidade da memória se dá em termos, já que as "nuvens" possuem, ao fim e ao cabo, materialidade concreta Ipor exemplo, localizam-se em uma sala de armazenamento de dados hermeticamente fechada em algum lugar do Vale do Silício).

4. No tocante à definição flusseriana do termo "código", Müller-Pohle defenderá a perspectiva de que apenas "o tecido de símbolos inteiramente criados pelo homem", ou seja, os produtos da cultura, poderiam ser denominados "códigos", excluindo, portanto, o "código genético”. Cf. ZIELINSKI (2015, p. 110). Todavia, no conjunto de palestras "Artifício, Artefato e Artimanha", bem como no ensaio "Arte Viva", Flusser, não apresenta essa distinção, tratando por código todo e qualquer elemento que possa ser manipulado artificialmente. 
5. Como adendo, no manuscrito intitulado "Jogos", redigido ainda no período de permanência no Brasil e no qual Flusser atentava para um modelo de ser-no-mundo baseado na figura do jogador (homo ludens), o poeta será caracterizado como um "aumentador de repertórios", ou seja, enquanto ente capaz de transformar ruídos e incorporá-los no universo dos jogos la língua, a ciência da natureza, a música a pintura

etc.).

6. "O fato é que no futuro não teremos mais de tomar decisões, mas preservaremos o direito de revogar as decisões tomadas automaticamente: o direito do 'não', do veto. Ora, pois é precisamente este direito de dizer 'não', o de vetar, que constitui a liberdade - porque 'decidir' não é dizer 'sim' para determinada alternativa, mas dizer 'não' a todas as demais alternativas." (FLUSSER, 2008b, p. 137).
Diante desse novo contexto "operacional" da arte enquanto artifício, a figura do poietés (no largo espectro que esse termo possui no contexto flusseriano) não mais deverá ser considerada apenas sob o viés de um tradutor de silêncios, tal como fora outrora caracterizada ${ }^{5}$. Doravante, poeta é o técnico dos códigos pós-alfabéticos. É, sobretudo, informador e permutador, duas qualidades, que, em conjunto, ressaltam a capacidade do artista não apenas em produzir novos ruídos (ponto de vista transcendente), mas também de, através do auxílio de aparelhos e programas, variar as informações a partir dos modelos de realidade existentes, como, por exemplo, a criação biotécnica de "seres que sintetizam características zoológicas com botânicas” (FLUSSER, 1998, p. 86), ou então, a criação de obras a partir do "jogo do acaso da permutação", no qual o papel do artista é o de escolher, dentre os processos computados, aqueles que lhe sejam mais apropriados - nesse caso, o artista passaria a ser um filtro ante os processos automatizados de criação ${ }^{6}$. Como observa Flusser,

\begin{abstract}
O novo poeta, munido de aparelhos alimentados digitalmente, não pode ser tão ingênuo. Ele sabe que tem de calcular sua experiência, decompôla em átomos de experiência, para poder programá-la digitalmente. E, nesse cálculo, ele deve averiguar o quanto sua experiência já seria prémodelada por outras. Ele não se reconhece mais como "autor", mas como permutador [Permutator]. Também a língua que ele manipula não lhe parece mais material bruto que se acumula em seu interior, mas ele a vê como um sistema complexo que lhe chega para ser permutado por ele. Sua atitude em relação ao poema não é mais a do poeta inspirado e intuitivo, mas a do informador [Informator]. Ele fundamenta-se em teorias e não faz mais poesia empiricamente (FLUSSER, 2010, p. 88).
\end{abstract}

Cabe notar, uma vez mais, a semelhança evidente da concepção de arte variacional em Flusser, bem como das transformações desencadeadas pelo assentamento da cultura imaterial, com a teoria estético-informacional de Abraham Moles. Para o pensador francês, "a arte permutacional [...] repousa sobre uma combinação de elementos simples propondo um campo de possíveis e um algoritmo a ser explorado"; desta feita, "a função do artista torna-se intelectualizada, seu contato com a matéria, antes essencial, perde a sua importância e ele se apoia enormemente sobre as novas técnicas de ação sobre a natureza” (MOLES, 1968, p. 76). O trabalho do artista será baseado cada vez mais na sequência controlada de informações: "eles fabricam programas" (Ibidem, p. 76). Moles ressalta também um novo papel para o esteta como "homem de laboratório", o qual, em conjunto 
com os produtores de arte, deverá definir as "regras de percepção da originalidade nas obras, os mecanismos sociodinâmicos de difusão, as leis combinatórias, algoritmos da programação de máquinas” (Ibidem, p. 78). Segundo Campanelli, o que se estabelece é uma cultura do remix:

[...] qualquer diálogo pressupõe a existência de informações contidas em alguma memória, armazenadas por meio de um discurso que as pronunciou (transmitiu). Em outras palavras, o ponto estabelecido por Flusser é que toda informação é uma síntese de informações anteriores; [...] a partir desse pressuposto, ele afirma que os seres humanos não criam, mas jogam com informações precedentes. (CAMPANELLI, 2015, p. 109, tradução minha)

Em linhas gerais, a história da cultura se converte aqui na história do desenvolvimento de técnicas (ou artes) capazes de investir os seres humanos da posição de agentes libertos do determinismo da realidade. Tal processo desembocará, acredita Flusser, em uma completa artificialização do mundo e do ser humano. Entra em cena um novo grau de desenvolvimento da cultura, rumo à imaterialidade, na qual o ser humano passará a ser artífice capaz de manipular (programar) radicalmente o mundo, de agora em diante visto como conjunto de dados ou informações.

Ao final, diante das diferentes concepções da arte na obra de Flusser, acreditamos não haver propriamente uma ruptura radical em seu pensamento. De seus escritos iniciais, voltados para uma ontologia da arte, passando por uma transição existencial que percebe, nas mutações do tecido social, um elevado grau de aparelhamento, culminando, por fim, em uma visão estética mais "tecnicista" - em todos esses momentos encontraremos uma preocupação que justifica o seu propósito, qual seja: o de evidenciar uma arte que provoque um descolamento/deslocamento do real. Se bem analisada a morfologia aqui apresentada, poderíamos arriscar que os escritos finais se conectam aos escritos iniciais, pois apresentam o mesmo movimento: se antes o poeta-artista mergulhava no silêncio para retraduzilo em realidade, também o artista "programador" faz a sua incursão, por meio dos aparelhos, no nada irrealizado, na zerodimensionalidade ${ }^{7}$. Continuaria, portanto, a executar um movimento exotérico ao explorar, nessa zona abismal, novas possibilidades de incrementar a trama da realidade.
174

Thiago Reis

As diferentes acepções da arte na obra de Flusser

7. Quando se refere à zerodimensionalidade, Flusser propõe uma interpretação filosófico-existencial do universo descrito pela teoria quântica enquanto realidade vazia, sem chão, constituída por pontos dispersos no vazio - enfim, realidade abismal-absurda. A zerodimensionalidade ou "vazio fundamental", acredita o filósofo, é o espaço através do qual uma nova imagem do mundo poderá ser constituída, ao modo de uma ficção, com o auxílio de aparelhos capazes de sintetizar ou manipular essa (pré-)realidade em mundos possíveis. 


\section{Bibliografia}

ADORNO, Theodor. Dialética negativa / trad. Marco Antônio Casanova. Rio de Janeiro: Zahar, 2009.

BLOCH, Ernst. 0 Princípio Esperança / trad. Nélio Schneider. São Paulo: Contraponto Editora, 2005, v.1.

CAMPANELLI, Vito. L'utopia di una società dialogica. Vilém Flusser e la teoria delle immagini tecniche. Luca Sossella Edizioni, 2015.

DUARTE, Rodrigo. Pós-história de Vilém Flusser: gêneseautonomia-desdobramentos. São Paulo: Annablume, 2012.

FLUSSER, Vilém. Artifício, Artefato, Artimanha. Manuscrito cedido pelo Arquivo Vilém Flusser São Paulo. Sem data, sem paginação.

FLUSSER, Vilém. Língua e Realidade. São Paulo: Herder, 1963.

FLUSSER, Vilém. Ficções Filosóficas. São Paulo: Editora da Universidade de São Paulo, 1998.

FLUSSER, Vilém. 0 mundo codificado. Por uma filosofia do design e da comunicação. São Paulo: Cosac Naify, 2008a.

FLUSSER, Vilém. 0 universo das imagens técnicas. Elogio da superficialidade. São Paulo: Annablume, 2008b.

FLUSSER, Vilém. Pós-história: vinte instantâneos e um modo de usar. São Paulo: Annablume, 2011 a.

FLUSSER, Vilém. Vampyroteuthis infernalis. São Paulo: Annablume, $2011 \mathrm{~b}$.

FLUSSER, Vilém. The Surprising Phenomenon of Human Communication. Metaflux Publishing, 2016.

FREUD, Sigmund. Mal-estar na civilização / trad. P. C. Souza. In: FREUD, Sigmund. Obras Completas de Sigmund Freud. São Paulo: Cia das Letras, 2010, v. 18, pp. 13-122.

MOLES, Abraham. L'esthétique experimentale dans la nouvelle société de consommation. Bit 1: the theory of informations and the new aesthetics, n.1, 1968, pp. 69-78. 
WITTGENSTEIN, Ludwig. Tractatus Logico-Philosophicus / trad. José A. Giannotti. São Paulo: Companhia Editora Nacional, 1968.
As diferentes acepções da arte na

obra de Flusser

ZIELINSKI, Sigfried. et al. (orgs.). FLUSSERIANA: an intellectual toolbox. Minnesota: Univocal, 2015. 
Thiago Reis é Doutor em Filosofia pela Universidade Federal de Minas Gerais (2018), Mestre em Estética e Filosofia da Arte pela Universidade Federal de Ouro Preto (2011). Docente do curso de Arquitetura e Urbanismo da Universidade de Uberaba. Desenvolve de 2019 e aceito em 4 de agosto de 2020 . pequisas na área de Estética e Filosofia da Arte, com ênfase no pensamento contemporâneo. 